\title{
Is Romania an Adaptable Country to Achieve Guidelines and Rule in Engineering Risk of Automotive Industry?
}

\author{
Dan-Mihai POPA* \\ Industrial Engineering, Politehnica University of Timisoara Timisoara, B-dul Mihai Viteazu, no.1, 300222,
} Romania

*Corresponding Author: Dan-Mihai POPA, Industrial Engineering, Politehnica University of Timisoara

Timisoara, B-dul Mihai Viteazu, no.1, 300222, Romania

\begin{abstract}
As general porpose we would like to follow based on this study straits, scopes, preferences and interest in order to look at Romania's with potential applied on guidelines, norms and evaluation criterias. Its current position to grow? Comparated with developing and developed countries we wanted to respond at several questions which are concerned not only to technology fields, our goal of Engineering Risks is to followed rules for digital assistants aimed at human well-being, these rules for engineering risks are the longterm goal. Finally, we attempted to identify the main barriers that seem to inhibit engineering risks normes applied in Romania somehow or orther, despite significantly growing R\&D intensities development.
\end{abstract}

Keywords: engineering risk, ISO16001, risk management, risk assessment, engineering of risk management

\section{INTRODUCTION}

The preponderant tendency in automotive industry is to adapt permanently to the changes and introduce the market tendency in the new products that leads to customer satisfaction [1]. Understanding the automotive development life cycle is of paramount importance, before starting to construct any suitable tailored service process, which will be understood and accepted by the stakeholders. Effective process establishment "does not happen until an organization recognizes the need for it and the benefits it will bring them", i.e. [2].

Humans have always faced problems to solve otherwise they would not have advanced. We could attempt to categorise risk assessment or engineering risks into unique, lucrative, local, global, etc. while searching for the motivators that bring them to light. Regardless of their origin, however, developing and evaluation criteria are an expansion of human crativity, concentration, reasoning and critical/creative thinking [3].

Passenger cars Light commercial vehicles up to $3.5 t$

Medium and heavy commercial vehicles over $3.5 \mathrm{t}$

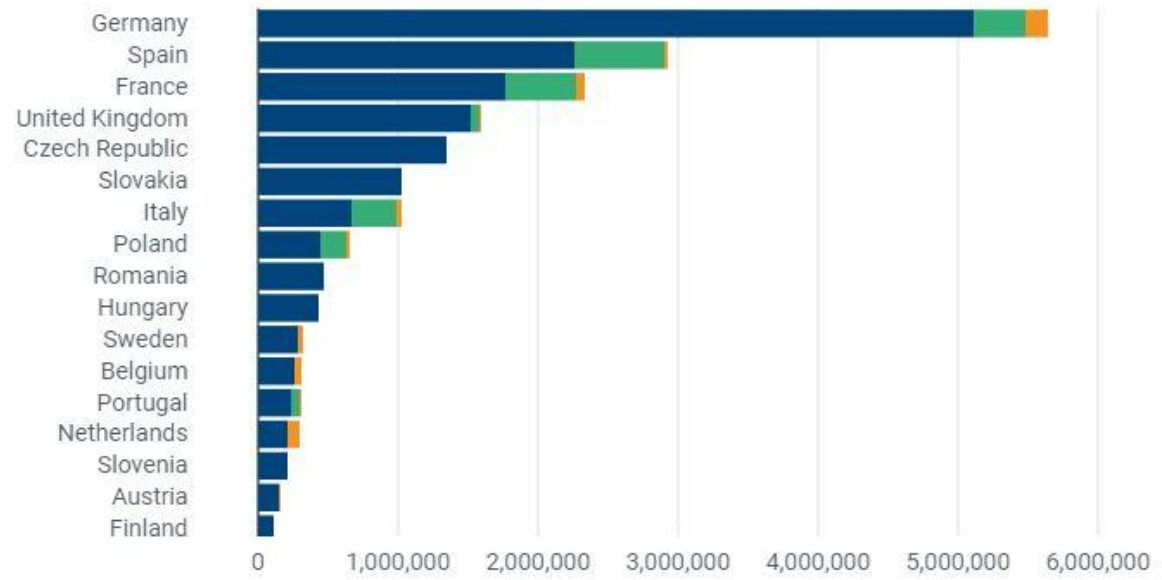

Figure1. Motor vehicle production in the EU, according with European Automobile Manufacturers Association Source [7] 
Romania, with is $19.2 \mathrm{M}$ inhabitants, is the $6^{\text {th }}$ largest country on the European Union by population, after Germany, France, Italy, Spain and Poland [4]. In 2014 there were 153,500 Romania university graduates and 32,500 of them graduated from technical universities, which makes $21,2 \%$ of all graduates [5]. Moreover, Romania R\&D intensities expenses represented $0.51 \%$ of the GDP, of which $0.30 \%$ for the private sector. In 2018, Romania spent 986 M EUR on the research and development activity. At the end of 2018, 44733 employees were involved in the research and development activity, a level that was comparable to the one recorded at the end of 2017 [6].To assets if the Romania potential expressed by its population, R\&D personnel, number of university graduates and growing investment in the $R \& D$ investments in the $R \& D$ sector correlates with adaptable guidelines and rules on the Engineering Risks of Automotive Industries we need to analyzed statistics publish by European Comunitee and Automotive Sector in Europe. Several statistics shall be follows: motor vehicle production in Europe and how Romania vehicle production sector situated in Europe, both answer as illustrated in Figure 1.

\section{RESEARCH METHODOLOGY}

The Motor vehicle production development in Romania includes ADAS sector, HMI sector or IBS sector, these sectors are grows up in every year; the main projects on the R\&D development are focused on the sensor projects [8]. On this study we are talking about how the R\&D activities are correlated with international standers for identified risk and monitor zed risk. The study was conducted on a sample of 33 persons with activity in different industry but sectors such as: automotive, audit, human resources with the following characteristics:

H1: urban environment;

$\mathrm{H} 2$ : $\quad$ age between 22 and 40 years;

H3: $\quad 36.36 \%$ are women and $63.63 \%$ are men;

H4: $\quad 99.99 \%$ are employee;

Two methods of population extraction were used: opportunity-based sampling (representing companies from the 3 large geographical regions of Romania: Wallachia, Transylvania and Moldova) and simple random sampling (randomly included employees from all departments of participating organizations).Reports 1 and 2 present number of employees from companies and field of domain activities, respectively. Data analysis was made on January-March 2019 with platform iSondaje an Romanian survay platform [9].

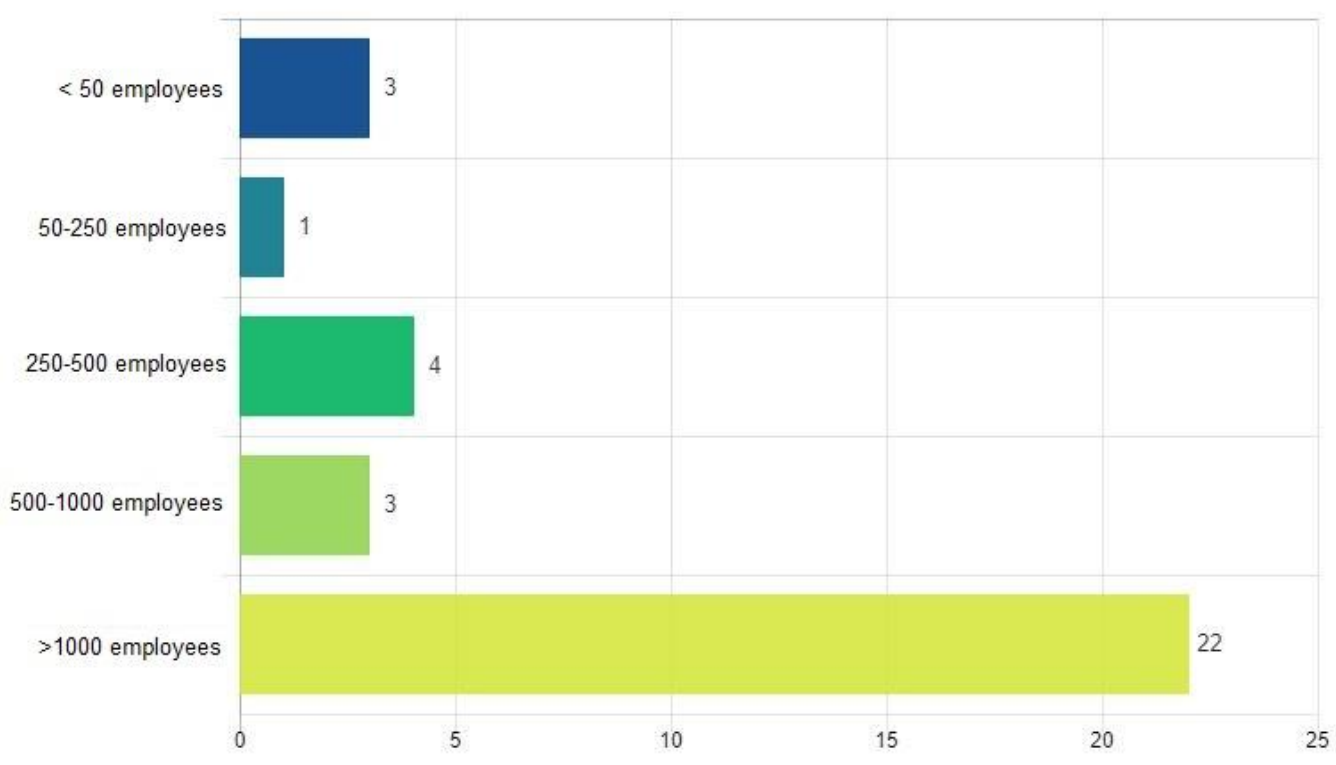

Figure2. Number of employees from companies participating at survey

Source: Author analysis based on [9] 
Is Romania an Adaptable Country to Achieve Guidelines and Rule in Engineering Risk of Automotive Industry?

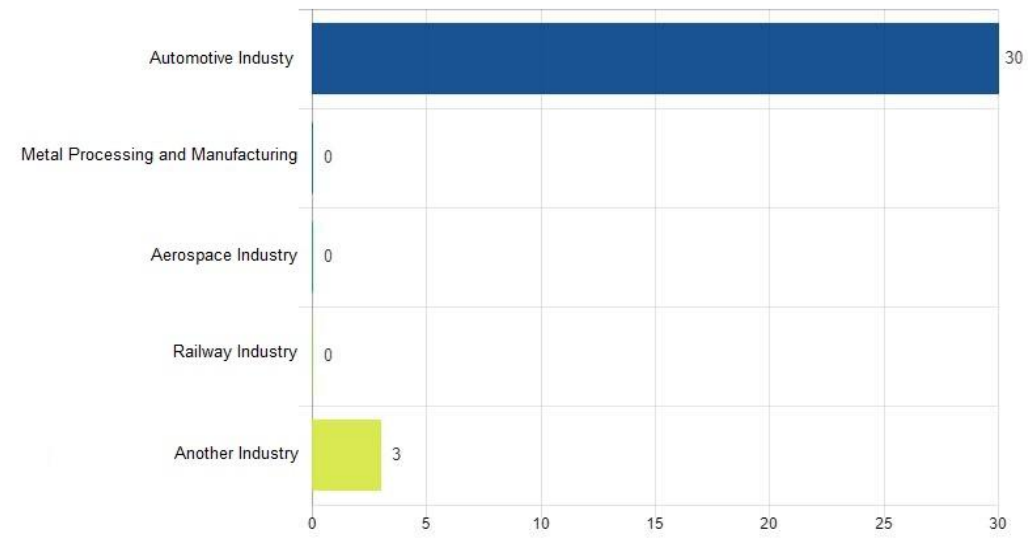

Figure3. Fields of domain activity from companies' participating at survay

Source: Author analysis based on [9]

The preponderant tendency in automotive industry is to adapt permanently to the changes and introduce the market tendency in the new products that leads to customer satisfaction [1].

The available report [11] indicate that largest decreases in industrial producer prices were observed in Italy $(-3.1 \%)$, Estonia and Portugal (both $-2.6 \%$ ), while the highest increases were recorded in Greece $(+4.7 \%)$, Bulgaria $(+4.5 \%)$ and Romania $(+4.4 \%)$. This positive outlook is sustained with arguments which include competitive wages, an educated and productive labor force and ongoing investment in manufacturing [1]. Data analysis from Figure 4 revealed that products developed in the companies can differ.

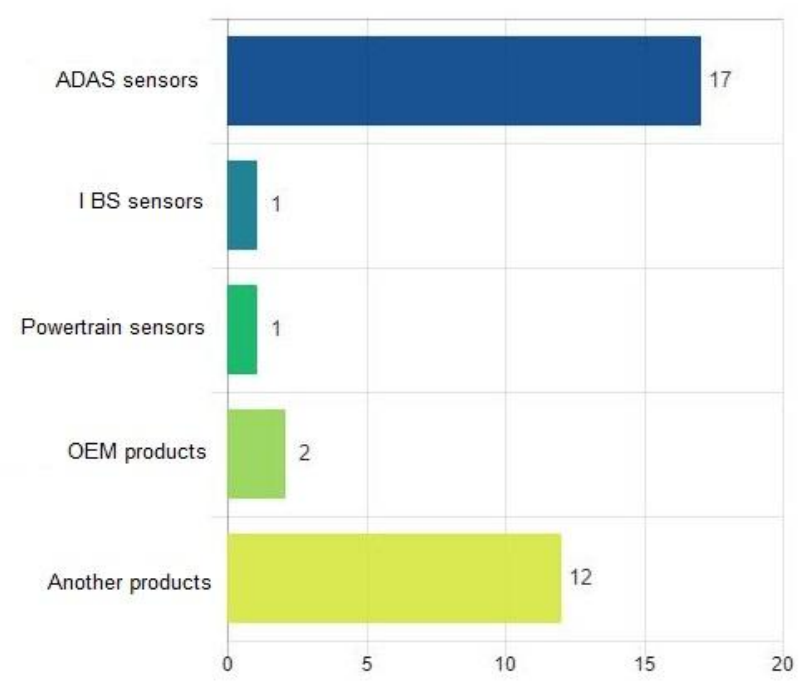

Figure4. Products developed by companies

Source: Author analysis based on [9]

On the incipient phase of project, on quotation project a lot of times risk planning is not taken in consideration by management engineering, because on Automotive Industry in Romania the standards such as: IATF 16949, ISO31000 and ISO 31010, are left aside because in the quotation phase is very hard to find a risk assessment evaluator and is too expensive to pay for this type of evaluation. In fact, this quotation can be lost into the detriment of another competitors, not from financial reasons, but from technical causes (product performance) of planning causes (final delivery to customer) [10].

The applicability of these standards which are mentioned above are showns on the Figure 5, based on the survay analysis. 


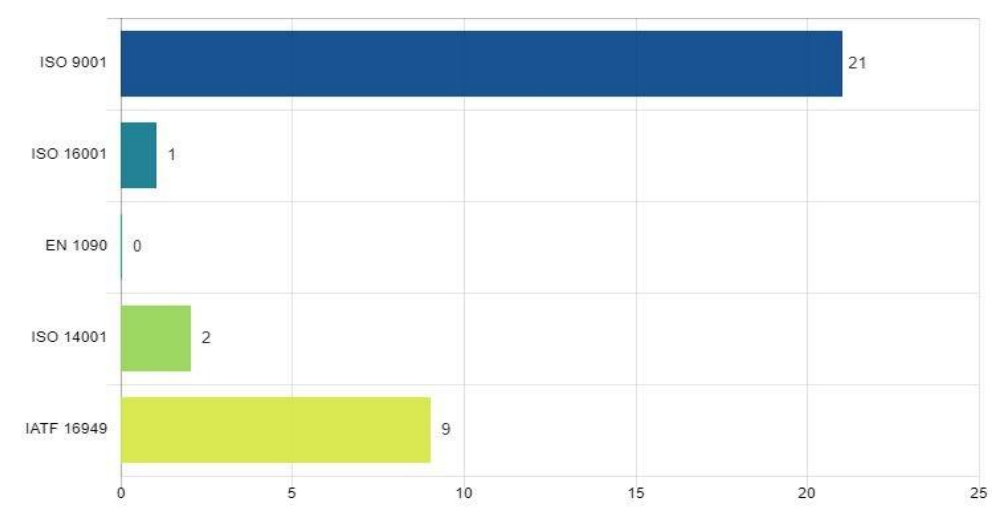

Figure5. Standards applied by companies

Source: Author analysis based on [9]

\section{RESULTS AND DISCUSSION}

\subsection{Results}

Based on the findings presented in this study we found that international standards are applied just on the largest companies like cars producers (Dacia, Ford), TIER 2 suppliers (Continental Automotive, Hella, Dura, TRW, Mahle), TIER 3 suppliers (Thomas, Dedienne, Hock). All these companies have started to grow in the automotive directions because many of them start to develop their business by 15 years in Romania according with standard and norms, these companies are consider that have many of employees matured. Figure 6, showns how many of companies have applied an standard related to engineering risk on their side and Figure 7 indicate how many companies have on their plan to implement such us engineering risk standards.

In automotive industry the development of new products, involve complex engineering processes subject to time pressures and fierce competition on the automotive market. An important role in the development of such projects it is the process planner. The position of process planner involves the interface between the department of design and development and production department, managing the projects in terms of technical side till implement them in series production [12]. In another case study of engineering risk in automotive industry was discussed about the engineering of risk management is placed and how its implementation has been tried in multinational companies in automotive industry from Romania. A large number of companies don't use a strategy to avoid the engineering risk in their design products [8].Engineering risk is linked also to safety and security engineering are very closely related disciplines and could greatly benefit from one another if adequate interactions are defined. Both disciplines focus on system-wide features and should be integrated into the development process from the initial phases and onwards. Safety engineering is already an integral part of automotive engineering and safety standards are well established in the automotive industry [13].

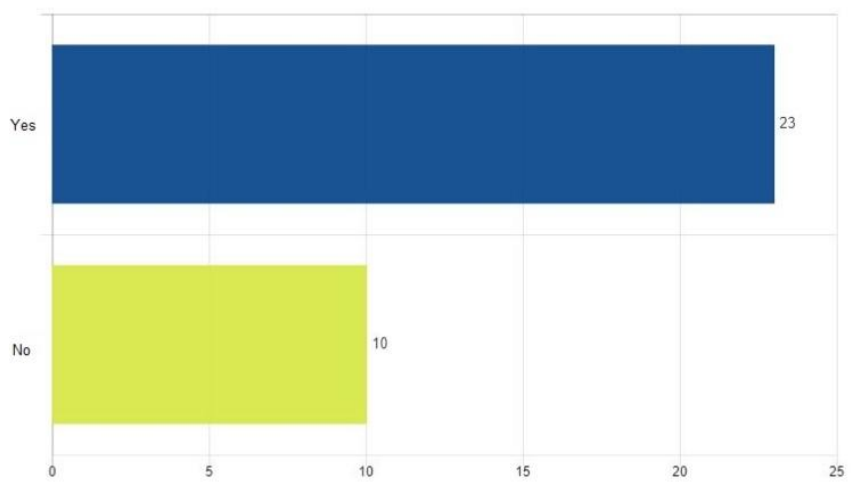

Figure6. Companies have applied an standard related to engineering

Source: Author analysis based on [9] 
Is Romania an Adaptable Country to Achieve Guidelines and Rule in Engineering Risk of Automotive Industry?

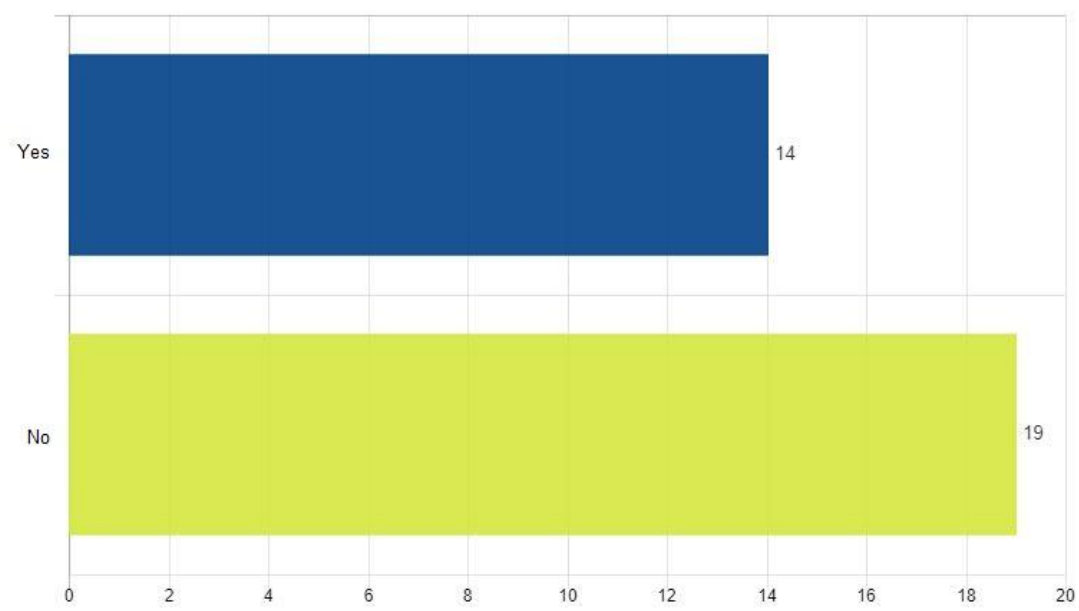

Figure7. Companies have in plan to implement an standard related to engineering Source: Author analysis based on [9]

\subsection{Discussion}

The large number of Romania technical universities and the Romania Ministry of Higher Education have a low interest to introduced some disciplines' relevant to help their graduates in supporting the transition from engineering education through concurrent engineering on the competitive economy. Despite on the "preasure" from in dusty companies to made students competitive the support from technical universities is still little. On the in West region of Romania where companies requested graduates students, Tier 2 companies like Continental, Flex or Hella tried to made an partnership with technical universities and their researchers to deliver reasults which are commercially feasible with porpuse to organised courses and summer school practice in every year.

At other problems, not discussed in this paper, the change request came from customer because they want some changes after serial production was released sometimes caused problems or series production in Automotive Industries based on problems caused by supplied chain of products when a strong process to avoid engineering risk problems is missing $[8,10]$.

\section{CONCLUSiON}

The results of the study conclude that corporation company's can influence the business strategy and performance and they can support academic and technical universities to growned from engineering education through concurrent engineering on the competitive economy. This shows that the higher risks reval details of different levels and high risk can by caused when this standards are not applied and monitorized.

To build human capital capable of engineering risks problems which will be supportive to companie's together with technical universities, it is necessary to made an collaboration on the long term and to improve this procedures to increase awarnessamong the technical university and management risk problems.

These tools can help to prioritize actions considerably and can be effective in increasing the value

of those actions: Ishikawa diagram, 5 why method, IATF 16949, ISO31000 and ISO 31010 shall be used like pair comparasion and ranking them in a suitable manner and all these methods on the engineering risk which can decice properly a decision making problem into a quantitative form, and it also transforms mental assessments into relative values.

\section{REFERENCES}

[1] C. G. Lixandru, "Supplier Quality Management for Component Introduction in the Automotive Industry", SIM 2015: 13th International Symposium in Management, Management During and After the Economic Crisis, 9-10 October 2015, Timisoara, Romania

[2] ITIL3 Service Transition, ISBN 978011331048 7, Copyright 2007 
Is Romania an Adaptable Country to Achieve Guidelines and Rule in Engineering Risk of Automotive Industry?

[3] Dorota Chybowska, Leszek Chybowski and Valeri Souchkov, It Poland an Innovative country, Management Systems in Product Engineering, 2018, Volume 26, Issue 1, pp 35-41, DOI: https://doi. org/10.2478/mspe-2018-0006

[4] Worldometers website. (2020, April 17). Countries in Europe by population [Online]. Available: https://www.worldometers.info/population/countries-in-the-eu-by-population/

[5] Central Statistical Office, "Funding of the enrollment figure for the academic year 2018-2019". Website: http://www.cnspis.ro/

[6] Central Statistical Office, "The research and development activity in 2018”. Website: https://insse.ro/

[7] European Automobile Manufacturers Association Website, "Motor vehicle production in the EU", Available: https://www.acea.be/statistics/tag/category/eu-production

[8] D. M. Popa, "Case study of Engineering Risk in Automotive Industry", Management Systemsin Production Engineering, 2018, Volume 26, Issue 1, pp 27-30, DOI: https://doi.org/10.2478/mspe-20180004

[9] iSondaje, Website: http://www.isondaje.ro/surveys/

[10] D. M. Popa, "Engineering Risk of series production in Automotive Industry", Management Systemsin Production Engineering, 2019, Volume 27, Issue 1, pp 5-11, DOI: https://doi.org/10.1515/mspe-2019-0001

[11] Eurostat website, Industrial producer prices stable in both euro area and EU27, Website: https://ec.europa. eu/eurostat/documents/2995521/10159436/4-04022020-AP-EN.pdf/7d067c86-8df4-a434-f0c1$8688 \mathrm{dbac} 8239$

[12] L. Margineanu, G. Prostean and S. Popa. "Conceptual model of management in automotive projects", in Proc. of 7th World Conference on Educational Sciences, vol. 197, 2015, pp. 1399-1402.

[13] G. Macher, E. Armengaud, E. Brenner and C. Kreiner. "Threat and Risk Assessment Methodologies in the Automotive Domain", in Proc. of $1^{\text {st }}$ Workshop on Safety \& Security Assurance for Critical Infrastructures Protection (S4CIP), vol.83, 2016, pp. 1288-1294.

\section{AUTHOR'S BIOGRAPHY}

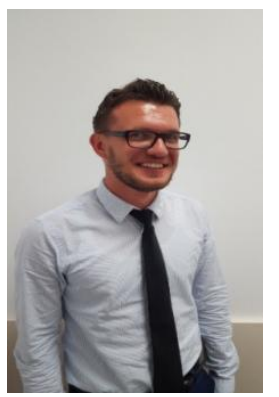

Dan Mihai Popa, I have been working in automotive industry since 2010 mainly in Mechanical Design for mechanical parts and sensors from automotive industry. In variety of technical and customer projects I gain experiences with team management, suppliers and customer's visits, leading and coaching teams directly or in remote mode.

I'm located in West region of Romania; however I travel a lot to EU countries, China, USA, to coach colleagues and to begin new projects with my team members.

I'm social person, good when working in a team, with a leader spirit. Keen on learning new things. Always wanting to get better. Passions for mechanics, good 3D perspective, practice and very pragmatic and I never back-down from responsibilities.

Citation: Dan-Mihai POPA. “Is Romania an Adaptable Country to Achieve Guidelines and Rule in Engineering Risk of Automotive Industry?" International Journal of Managerial Studies and Research (IJMSR), vol 8, no. 4, 2020, pp. 25-30. doi: http:// dx.doi.org/10.20431/2349-0349.0804003.

Copyright: (C) 2020 Authors. This is an open-access article distributed under the terms of the Creative Commons Attribution License, which permits unrestricted use, distribution, and reproduction in any medium, provided the original author and source are credited. 